\title{
Management of ANCA-associated vasculitis: Current trends and future prospects
}

This article was published in the following Dove Press journal:

Therapeutics and Clinical Risk Management

10 June 2010

Number of times this article has been viewed

\section{Sally Hamour \\ Alan D Salama \\ Charles D Pusey \\ Imperial College Kidney and Transplant Institute, Imperial College, London, UK}

Correspondence: Charles Pusey Imperial College Kidney and Transplant Institute, Imperial College London,

Hammersmith Hospital Campus, Du Cane Road, London WI2 ONN, UK Tel +44208383 3I52

Fax +442083832062

Email c.pusey@imperial.ac.uk

\begin{abstract}
The antineutrophil cytoplasm antibody (ANCA)-associated vasculitides are a spectrum of heterogeneous autoimmune diseases characterized by necrotizing small vessel vasculitis and the presence of ANCA. These chronic multisystem disorders may be life-threatening if there is major organ involvement, such as acute renal failure or pulmonary hemorrhage, and require significant initial immunosuppression and long-term maintenance treatment. Long-established protocols using cyclophosphamide and prednisolone have resulted in dramatically improved outcomes for patients since the 1970s. Subsequently, international collaboration has contributed to a growing evidence base and consensus in the management of these rare disorders. Modifications to traditional treatment protocols by the use of azathioprine or methotrexate rather than cyclophosphamide, and the introduction of newer agents, such as rituximab, has maintained outcomes whilst decreasing toxicity. However, the treatment limitations of incomplete efficacy, infection, and cumulative toxicity persist. These issues have continued to drive the search for safer and more effective modulation of the immune system using targeted immunotherapy. This review will explore the current evidence base for management of ANCA-associated vasculitis and future treatment prospects.
\end{abstract}

Keywords: ANCA, vasculitis, treatment

\section{Introduction}

The antineutrophil cytoplasm antibody (ANCA)-associated vasculitides (AAV) are characterized by the production of ANCA, reactive to either proteinase-3 (PR3-ANCA) or myeloperoxidase (MPO-ANCA), which are constituents of neutrophil granules and monocyte lysosomes. AAV are idiopathic multisystem vasculitides which cause destructive inflammation of mainly small caliber arterial vessels and comprise several clinically and pathologically defined disease entities: Wegener's granulomatosis (WG), microscopic polyangiitis (MPA), renal-limited vasculitis (RLV) and Churg-Strauss syndrome (CSS).

AAV cause considerable morbidity and mortality, with end-stage renal failure developing in over $20 \%$ of patients at five years. ${ }^{1}$ Prior to the introduction of steroids and cyclophosphamide (CYP) in the early 1970s, survival was uniformly dismal, with a median survival of five months for patients with generalized WG. ${ }^{2}$ In contrast, induction of remission is now achieved in over $90 \%$ patients by six months, ${ }^{3}$ and five-year survival rates are around $75 \% .{ }^{4}$ However, even with best available therapy, relapse rates remain unacceptably high at up to $50 \%$ over five years, ${ }^{5}$ as does treatment-related morbidity and mortality. 
Long-term management of these conditions therefore requires balancing the burden of immunosuppression with control of disease activity, and the impetus remains to refine these protocols and to investigate newer agents that might be equipotent but less toxic. A robust evidence base for treatment regimens has historically been limited. However, the European Vasculitis Study Group (EUVAS) has fostered international collaboration and conducted prospective studies addressing optimal therapy that have led to some treatment consensus. Factors initiating disease and causing relapse remain poorly defined and therefore it is imperative to understand the pathogenesis of these conditions better, so that more targeted and less toxic therapeutic protocols can be devised.

\section{Clinical features}

AAV are characterized by a focal necrotizing vasculitis affecting arterioles, capillaries, and venules which can affect virtually any organ with varying degrees of severity. Overall, the lungs (Figure 1) and kidneys (Figure 2) are the most commonly involved organs, in around $70 \%-80 \%$ of patients. ${ }^{6}$ There is heterogeneity between and within disease entities in relation to extent and prognosis, and the Chapel Hill Consensus Conference nomenclature ${ }^{7}$ is one of the most widely used vasculitis classification systems. AAV most commonly occur in the elderly and the incidence is approximately 20 cases/million/year. ${ }^{8}$

WG is characterized by granulomatous inflammation of the upper and lower respiratory tract and a high rate of relapse.

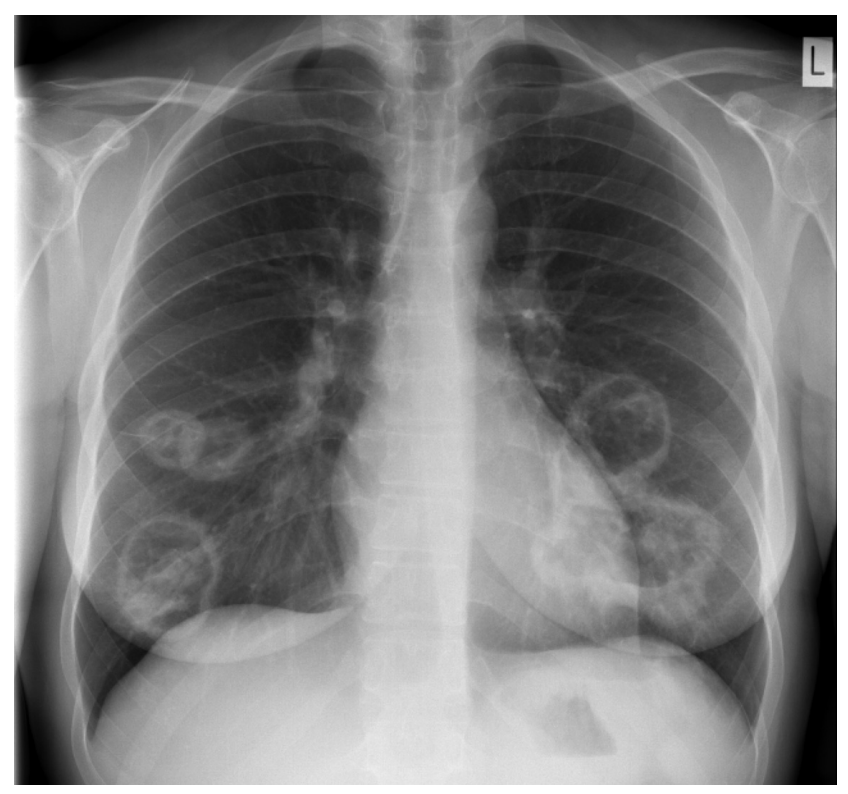

Figure I Chest radiograph showing multiple cavitating lung lesions in a patient with Wegener's granulomatosis.

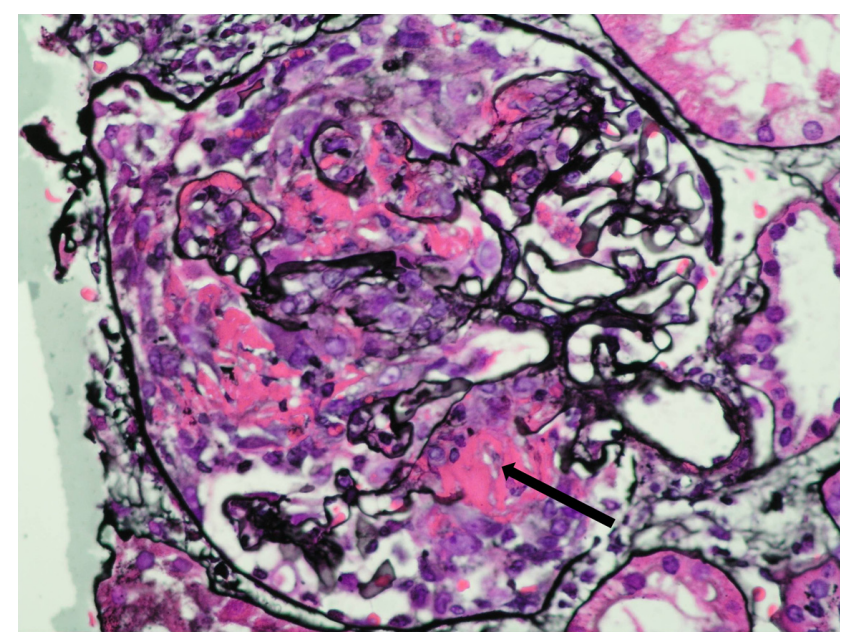

Figure 2 Renal biopsy from a patient with $A A V$ and severe renal failure showing a glomerulus containing an extensive cellular crescent with a break in the basement membrane and surrounding fibrin deposition (arrowed) Methenamine silver stain, X400. Abbreviation: AAV, ANCA-associated vasculititis.

Granulomatous lung disease may be difficult to distinguish from mycobacterial infection. Ear, nose and throat disease in WG may be aggressive, with classical necrosis and collapse of the nasal bridge, epistaxis, conductive deafness due to Eustachian tube dysfunction, or subglottic stenosis. Orbital disease in WG includes necrotizing scleritis and primary orbital disease which may present with proptosis. Both of these features and their attendant complications may pose a severe risk to vision. WG is usually associated with PR3-ANCA. In contrast, patients with MPA have small vessel inflammation without granulomata, more often with MPO-ANCA. CSS is characterized by late-onset asthma and eosinophilia, sometimes with rhinitis or nasal polyps, and ANCA more usually reactive to MPO. Renal-limited vasculitis is an isolated pauci-immune crescentic glomerulonephritis in which MPO- or PR3-ANCA may be found.

Patients with generalized disease may present with active renal vasculitis or another immediate threat to life or organ function. Without treatment, the most serious complications of pulmonary hemorrhage and rapidly progressive glomerulonephritis may be rapidly fatal. Limited disease refers to patients with AAV and one or more involved organ systems, but no renal disease or immediately life-threatening complications (Table 1). ${ }^{9}$ The intensity (and therefore tolerated potential toxicity) of treatment depends on disease severity. Interestingly, only about $60 \%$ of patients with limited disease will be ANCA-positive and more than $10 \%$ of patients with pauciimmune glomerulonephritis thought to be due to AAV will be ANCA-negative. ${ }^{10}$ Overall, the accumulation of chronic tissue damage with fibrosis and scarring contributes significantly to morbidity. Patients are closely monitored by review of clinical 
Table I EUVAS disease categorization of ANCA-associated vasculitis 9

\begin{tabular}{ll}
\hline Category & Definition \\
\hline Localized & $\begin{array}{l}\text { Upper and/or lower respiratory tract } \\
\text { disease without any other systemic } \\
\text { involvement or constitutional symptoms } \\
\text { Any, without organ-threatening or life- } \\
\text { threatening disease }\end{array}$ \\
Early systemic & $\begin{array}{l}\text { Renal or other organ threatening disease, } \\
\text { serum creatinine }<500 \mu \mathrm{mol} / \mathrm{L}(5.6 \mathrm{mg} / \mathrm{dL})\end{array}$ \\
Generalized & $\begin{array}{l}\text { Renal or other vital organ failure, serum } \\
\text { creatinine }>500 \mu \mathrm{mol} / \mathrm{L}(5.6 \mathrm{mg} / \mathrm{dL})\end{array}$ \\
Severe & $\begin{array}{l}\text { Progressive disease unresponsive to } \\
\text { glucocorticoids and cyclophosphamide }\end{array}$ \\
Refractory &
\end{tabular}

symptoms and signs, urinalysis, and imaging and laboratory blood tests, including autoantibody levels by indirect immunofluorescence for ANCA or antigen-specific ELISA for antiPR3 or anti-MPO antibodies. Disease activity and severity may be assessed using the well-characterized Birmingham Vasculitis Activity Score, ${ }^{11}$ while disease-induced damage is measured by the Vasculitis Damage Index. ${ }^{12}$ These scores have been mostly used as research and clinical trial tools enabling comparison of patients, but may be used to facilitate patient management.

\section{Pathogenesis}

Both cellular and humoral arms of the immune system are involved in the disease. The production of ANCA is a hallmark of the small vessel vasculitides. However, T-cells, macrophages, and other components of the immune system have all been implicated in causation of disease. Better understanding of pathogenesis is clearly required to develop a treatment rationale for specific immunotherapies. However, it is unclear to what extent these heterogeneous conditions share similar pathologic mechanisms. ANCA are specific for the serine protease PR3 or for MPO, both of which are constituents of azurophilic neutrophil granules and monocyte lysosomes. In vitro studies indicate that cytokine-primed neutrophils and monocytes express PR3 and MPO on their cell membranes. ANCA bind to the cell surface by both Fc receptor engagement ${ }^{13}$ and (Fab') 2 binding, ${ }^{14}$ thereby activating the cell. Neutrophils activated by ANCA release oxygen radicals, lytic enzymes, and inflammatory cytokines, such as IL-8. ${ }^{15,16}$ This in turn impedes neutrophil migration ${ }^{17}$ and results in excessive neutrophil accumulation within the vasculature, allowing the released reactants to damage the endothelium and cause vessel inflammation. ${ }^{18}$ The normal process of noninflammatory clearance of apoptotic neutrophils by professional phagocytes is disrupted by $\mathrm{ANCA}^{15,19}$ and, as a result, neutrophils are likely to undergo proinflammatory secondary necrosis. The presence of ANCA has been shown to promote adhesion and transmigration of primed neutrophils across tumor necrosis factor (TNF)stimulated endothelium. ${ }^{17}$

The most compelling in vivo evidence for the pathogenicity of ANCA in humans comes from a single case report of pulmonary hemorrhage and glomerulonephritis in a neonate with transplacental transfer of ANCA IgG from a mother with active MPO-ANCA vasculitis. ${ }^{20}$ Furthermore, recent in vivo animal models of MPO-ANCA vasculitis suggest that, at least in the rodent, MPO-ANCA are sufficient to generate glomerulonephritis and renal vasculitis, in the absence of antigen-specific T-cells. ${ }^{21}$ In addition, the renal injury in this model is dependent on complement activation ${ }^{22}$ and on the presence of neutrophils. ${ }^{23}$ In rats injected with MPO, MPO-ANCA are associated with focal necrotising glomerulonephritis, enhance leucocyte-endothelial interactions, and promote microvascular injury. ${ }^{24}$ In wild-type mice, transfer of murine PR3-ANCA has been shown to amplify local inflammation, ${ }^{25}$ although no convincing model of PR3ANCA vasculitis has been reported. In addition, no cases of human disease transfer by PR3-ANCA have been reported.

What triggers the formation of ANCA is unknown, but a role for septic episodes preceding episodes of AAV has been suggested. ${ }^{26}$ This has received more attention recently with a proposed model of molecular mimicry between ANCA targets and bacterial fimbrial adhesion proteins. ${ }^{27}$ Patients with focal necrotizing crescentic glomerulonephritis have a high prevalence of circulating autoantibodies against lysosomal-associated membrane protein-2 (LAMP-2), a heavily glycosylated type 1 membrane protein involved in cellular adhesion and homeostasis, and the majority of these anti-LAMP-2-positive patients are also ANCA-positive. Therefore, it is plausible that an early immune response to pathogen-derived peptides which show significant homology with peptide sequences in ANCA target antigens results in immune cross-reactivity. A central role for infections as triggers of disease has also been suggested following the description of anticomplementary PR3 antibodies in a proportion of patients with PR3-ANCA vasculitis. ${ }^{28}$ These antibodies react to peptide sequences from the complementary PR3-sequence, which has significant homology with a number of infectious pathogens, including Staphylococcus aureus, previously implicated in disease relapse. ${ }^{29}$ It has been proposed that antibodies induced by infection, which are cross-reactive to the complementary PR3 peptide, can 
then act as immunologic templates for anti-PR3 antibodies. Regardless of the exact molecular mechanism operating, infections appear to be a critical stimulus for inducing immune responsiveness, and their prevention may promote prolonged disease-free remissions. ${ }^{30}$

Paradoxically, in patients with AAV, the renal lesions are pauci-immune, characterized by little or no immunoglobulin deposition, but cellular infiltration with T-lymphocytes and macrophages, ${ }^{31}$ and there is now significant evidence for the role of cellular mediators, particularly T-cells, in AAV. WG is characterized by granulomatous lesions, typical of a delayed-type hypersensitivity reaction and reflecting a cellular immune response. ${ }^{32}$ T-cells have been further implicated in the process because patients' lymphocytes show in vitro reactivity to PR3 or MPO autoantigens, ${ }^{33}$ and T-cell directed therapy can treat disease. ${ }^{34}$ Th17 cells are implicated in autoimmunity and are likely to play a role in the pathogenesis of AAV. Work in our laboratory has shown that patients with AAV have elevated levels of IL-17 and some patients have ANCA-specific memory Th17-cells. ${ }^{35}$ Monocyte activation has also been demonstrated in AAV, with elevated levels of IL-6 and neopterin in acute disease but not in convalescence. ${ }^{36}$

In terms of genetic risk determinants, patients with WG have higher than expected carriage of the $\mathrm{Z}$ allele for the protease inhibitor gene, which confers $\alpha 1$-antitrypsin deficiency. ${ }^{37}$ Single nucleotide polymorphisms in the IL-2 receptor have been associated with systemic lupus erythematosus (SLE) and also with AAV, ${ }^{38}$ and CTLA4 and PTPN22 have been identified as susceptibility loci in AAV. ${ }^{39}$ Patients with AAV and PR3-ANCA have higher neutrophil membrane expression of PR3 which is genetically determined and related to relapse. ${ }^{40}$ Finally, analysis of leucocyte gene expression profiles in patients has demonstrated that ANCA signature genes are expressed on neutrophils and can be differentiated from healthy donors and patients with SLE. ${ }^{41}$ However, no clear link with major histocompatibility antigens has so far been demonstrated.

\section{Current treatment}

Treatment of AAV can be divided into two phases, ie, initial immunosuppression for rapid and effective onset of remission and subsequent maintenance therapy to prevent relapse. The ideal regimen would minimize toxicity whilst maintaining high levels of treatment success. The introduction of steroids and CYP in the 1970s transformed outcomes for patients with AAV, and subsequent multicenter randomized trials have optimized their use. Consensus regarding indications for plasma exchange (PE), the use of azathioprine (AZA) rather than CYP in maintenance treatment, and the introduction of methotrexate (MTX) for induction in less severe disease has come about as a result of trials conducted by EUVAS. However, despite significant evidence-based modification of standard treatment protocols, $90 \%$ of patients will experience drug-related toxicity, which is severe in $25 \%-50 \%$ of cases. ${ }^{42}$ Age and serum creatinine at diagnosis are the strongest predictors of both patient and renal survival, and elderly patients have significantly higher early mortality. ${ }^{5}$

\section{Induction therapy}

Advanced renal failure at presentation correlates with an increased risk of end-stage renal failure and death, and these patients are treated aggressively with CYP and high-dose intravenous (IV) steroids. However, this is associated with a significant risk of treatment-related morbidity and mortality, especially in older patients. Infectious adverse effects are the most common cause of death or severe morbidity, and their frequency is associated with increased age as well as steroid dosage and leucopenia secondary to immunosuppressive therapy. A diagnosis of WG, rather than MPA, and anti-PR3 rather than anti-MPO antibodies, are further markers of a poor prognosis, with increased risk of disease relapse. ${ }^{5}$ Therefore, intensity of treatment during the induction phase depends on both the extent and severity of disease, but almost invariably consists of glucocorticoids with a second agent. Serum creatinine, ANCA titer, and acute phase response all usually improve with induction treatment (Figure 3). Current EUVAS trials are attempting to define equipotent but less toxic induction regimens, based on the use of agents such

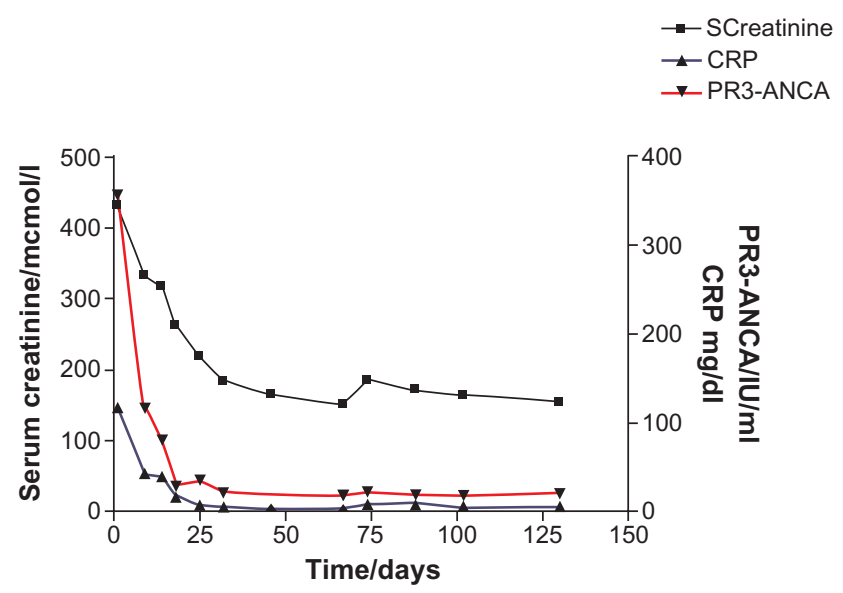

Figure 3 Biochemical changes over time in a patient with PR3-ANCA demonstrating rapid decrease in serum creatinine, ANCA titer and C-reactive protein following initiation of immunosuppression.

Abbreviations: ANCA, antineutrophil cytoplasm antibody; PR3-ANCA, proteinase-3 antineutrophil cytoplasm antibody. 
as rituximab (RTX) and mycophenolate mofetil (MMF, see www.vasculitis.org).

\section{Cyclophosphamide and glucocorticoids}

For many years, CYP has formed part of the usual high-dose regimen for induction of remission in severe disease. CYP is an alkylating agent which is an inactive cyclic phosphamide ester of mechlorethamine. It is transformed via hepatic and intracellular enzymes to active alkylating metabolites, ie, 4-hydroxycyclophophosphamide, aldophosphamide, acrolein, and phosphoramide mustard. The alkylated purine bases result in the inhibition of DNA and RNA synthesis and function, and eventually promote cellular apoptosis. Side effects of CYP are significant and cumulative, including short-term risks of hemorrhagic cystitis, leucopenia, and sepsis, as well as long-term risks of bladder cancer, lymphoproliferative disease, myelodysplasia, and gonadotoxicity.

The initial regimen was developed at the National Institutes of Health (NIH) and originally consisted of CYP at $2 \mathrm{mg} / \mathrm{kg} /$ day and glucocorticoids at $1 \mathrm{mg} / \mathrm{kg} /$ day. ${ }^{43}$ CYP was continued for at least one year after remission and steroids were tapered to an alternate day regimen, but also continued for one year. This regimen reliably induces remission in over $80 \%$ of patients, but causes significant toxicity and morbidity, ${ }^{6}$ and relapses occur in up to $50 \%$ of patients, despite continued immunosuppression. . $^{5,643}$ Numerous refinements of this approach have been tested in clinical trials. A number of randomised studies including the EUVAS CYCLOPS trial demonstrated that pulsed IV CYP at a dose of between 7.5 and $15 \mathrm{mg} / \mathrm{kg} / \mathrm{pulse}$ has the benefit of a lower total cumulative dose but is as effective as daily oral therapy in inducing remission. ${ }^{44}$ However, longterm relapse rates are likely to be higher, although the risk of leucopenia and sepsis is lower. The dose of CYP must be adjusted for weight, age, and renal function (Table 2). ${ }^{44}$ Mesna (2-mercaptoethanesulfonate sodium), which binds the toxic metabolite acrolein, and adequate prehydration, particularly before IV therapy, help to reduce the risk of bladder toxicity and hemorrhage.

Dosing of glucocorticoids has not so far been subjected to randomized trials, and a starting induction dose of $1 \mathrm{mg} / \mathrm{kg}$ is standard, with subsequent tapering to a maintenance dose of ideally not more than $10-15 \mathrm{mg} /$ day at three months or when remission is achieved, whichever is later. For rapid control of disease, pulsed IV methylprednisolone in doses of 0.5-1.0 g daily for three days is often used, but without supporting evidence. Side effects, including hypertension, obesity, hyperglycemia, cataracts, and osteoporosis, should
Table 2 Dose modification of pulsed intravenous CYP as used in the CYCLOPS trial ${ }^{44}$

\begin{tabular}{lll}
\hline \multicolumn{3}{l}{ Pulsed CYC dose reductions for renal function and age } \\
\hline Age (years) & \multicolumn{1}{l}{ Creatinine ( $\mu \mathrm{mol} / \mathrm{L})$} \\
\cline { 2 - 3 } & $<\mathbf{3 0 0}$ & $\mathbf{3 0 0 - 5 0 0}$ \\
\hline$<60$ & $15 \mathrm{mg} / \mathrm{kg} / \mathrm{pulse}$ & $12.5 \mathrm{mg} / \mathrm{kg} / \mathrm{pulse}$ \\
$60-70$ & $12.5 \mathrm{mg} / \mathrm{kg} / \mathrm{pulse}$ & $10 \mathrm{mg} / \mathrm{kg} / \mathrm{pulse}$ \\
$>70$ & $10 \mathrm{mg} / \mathrm{kg} / \mathrm{pulse}$ & $7.5 \mathrm{mg} / \mathrm{kg} / \mathrm{pulse}$ \\
\hline
\end{tabular}

See www.vasculitis.org/protocols/CYCLOPS.pdf

not be underestimated and remain a considerable cause of morbidity.

Prophylaxis against infection, peptic ulceration, and bone resorption should be standard during induction therapy. A combination of agents including Pneumocystis jiroveci prophylaxis with trimethoprim-sulphamethoxazole, topical oral antifungal treatment, a gastric protective agent, and calcium-vitamin D supplementation is usually added to the regimen. Biphosphonate therapy is contraindicated with more severe degrees of renal impairment but should be used when renal function permits.

\section{Plasma exchange}

$\mathrm{PE}$ is of additional benefit as induction therapy in severe renal disease. The EUVAS MEPEX trial compared pulsed IV methylprednisolone versus PE, in addition to standard treatment with oral CYP and steroids, in 137 patients with serum creatinine $>500 \mu \mathrm{mol} / \mathrm{L}$. It showed that PE decreased the risk of progression to end-stage renal disease by $24 \%$ at 12 months. ${ }^{45}$ Although the mechanism of this is likely to relate to rapid removal of ANCA, the depletion of circulating cytokines, complement, and coagulation factors may also be important. However, PE has not been shown to improve overall survival and it is not known whether or not it benefits patients with less severe disease. The proposed PEXIVAS project aims to study the influence of PE and of a reduced dose of steroids on mortality and ESRD in patients with less advanced renal impairment (estimated glomerular filtration rate of $<50 \mathrm{~mL} / \mathrm{min}$ ).

\section{Methotrexate}

MTX is a folic acid analog that inactivates the enzyme dihydrofolate reductase and thus the production of thymidylate, which is essential for DNA replication. MTX has similar success rates to CYP in induction of remission in early systemic vasculitis without significant renal disease. The EUVAS NORAM trial demonstrated that MTX is a less toxic alternative to CYP for patients with early systemic disease 
and serum creatinine $<150 \mu \mathrm{mol} / \mathrm{L},{ }^{46}$ achieving equal rates of disease remission, albeit at a slower rate. However, MTX is contraindicated in significant renal impairment because excretion is primarily by the kidney. Side effects include mucositis, pneumonitis, myelotoxicity, and hepatotoxicity. Dosage may begin at $10 \mathrm{mg} /$ week rising to $25 \mathrm{mg} /$ week or $0.3 \mathrm{mg} / \mathrm{kg}$ if tolerated, and patients should be given folate supplementation to minimize adverse reactions. Parenteral administration is preferred by some practitioners to minimize side effects and for rapidity of response.

\section{Mycophenolate mofetil}

MMF inhibits inosine monophosphate deydrogenase, an enzyme necessary for purine synthesis, which results in the inhibition of T- and B-lymphocyte activity. A recent small open-label study in China compared MMF and CYP for induction of remission in 35 patients, mainly MPO-positive, with serum creatinine $<500 \mu \mathrm{mol} / \mathrm{L}$. This showed higher rates of remission and maintenance of normal renal function in the MMF group (44\%) compared with the CYP group (15\%) at six months. ${ }^{47}$ The EUVAS MYCYC trial is comparing MMF and CYP for induction of remission but has yet to report the findings. There has been greater interest in the use of MMF as a maintenance agent, although recent IMPROVE trial results from EUVAS suggest it may be inferior to AZA. Gastrointestinal symptoms and opportunistic infections are not uncommon.

\section{Maintenance of remission}

Maintenance of remission in ANCA-associated vasculitis requires long-term immunosuppression in most patients. Therapy usually consists of long-term low-dose glucocorticoids together with a second agent. Optimum duration of treatment is unclear and this will be addressed by the EUVAS REMAIN study which will compare two years and four years of prednisolone and AZA maintenance after six months of stable remission. At present there is considerable variation in practice regarding withdrawal of immunosuppression; however, most expert practitioners would agree that treatment should be continued for a minimum of 18 months, and more usually a minimum of 24 months, particularly in PR3-positive patients, who have a higher relapse rate. ${ }^{48}$

\section{Azathioprine}

The original NIH regimen continued CYP for 12 months after remission. However, $50 \%$ of patients still relapsed, often coincident with a decrease in their immunosuppression dose, ${ }^{5,6}$ and long-term followup studies have shown the cumulative toxicity to be unacceptable. In a 27-year follow-up study of 145 patients with WG at NIH, there was a 33-fold increase in bladder malignancy, a 2.4-fold increase in other malignancies, an 11-fold increase in lymphoma, and infertility rates amongst women of $40 \%-57 \% .{ }^{6,49}$ Therefore, it was necessary to develop an alternative less toxic regimen. AZA has been widely used for maintenance in Europe, and is metabolized into thiopurine nucleotides by the liver, which interferes with the enzymes necessary for purine synthesis, leading to reduced cellular proliferation. In the EUVAS CYCAZAREM trial, ${ }^{3}$ AZA $2 \mathrm{mg} / \mathrm{kg} /$ day was as effective as CYP at maintaining remission, in combination with steroids, although short-term side effects were not reduced. In this randomized trial of 155 patients over 18 months, AZA was substituted for CYP at 3-6 months and compared with a year of CYP. The relapse rate was $17 \%$ in both groups and, as a result, a switch to AZA following induction of remission by CYP, usually achieved within 3-6 months, is now the commonest maintenance regimen in use. Side effects include leucopenia and hepatotoxicity.

\section{Methotrexate}

In the EUVAS NORAM trial, treatment for one year with CYP was compared with MTX (see earlier). At 18 months there was a $69.5 \%$ relapse rate in the MTX group compared with $46.5 \%$ in the CYP group, although this may be partly due to the trial design which stopped all immunosuppression at 12 months. ${ }^{46}$ However, other studies have found significant relapse rates with MTX of $37 \%$ at 25 months $^{50}$ and $50 \%$ at 32 months, ${ }^{51}$ which are not dissimilar to relapse rates with AZA or CYP. A direct comparison of AZA and MTX as maintenance therapy found no difference in adverse events or relapse rates at 12 months. ${ }^{52}$

\section{Calcineurin inhibitors}

Cyclosporin and tacrolimus are both calcineurin inhibitors which inhibit T-lymphocyte signal transduction and IL-2 transcription. Cyclosporin was historically the mainstay of immunosuppression for renal transplantation. The newer drug tacrolimus has since proven to be more effective in preventing rejection ${ }^{53}$ and has largely superseded cyclosporin. Despite their extensive use in transplantation, and in primary glomerulonephritides, the role of these drugs in systemic autoimmune diseases has not been systematically validated and there are no randomized trials of the use of calcineurin inhibitors in AAV. They are sometimes used 
as maintenance therapy when more myelotoxic drugs are contraindicated. Their potential utility may be inferred from the low relapse rates in transplantation, and successful use has been reported in case reports and small cohort studies in AAV. ${ }^{54,55}$ Cyclosporin has been used as second-line maintenance therapy in SLE in uncontrolled trials of small numbers with some effect ${ }^{56-58}$ and tacrolimus has been used in induction of remission in renal SLE ${ }^{59}$ However, recent collaborative trials in AAV have focused on evaluating the role of other agents such as MMF and RTX.

\section{Mycophenolate mofetil}

MMF is now routinely used long-term to prevent allograft rejection in renal transplantation because it has been proven to be superior to AZA. ${ }^{60}$ Consequently, there has been considerable interest in the use of MMF as a maintenance agent in place of AZA in vasculitis. One small prospective study of 14 patients showed that it was well tolerated, although $42 \%$ of patients relapsed. ${ }^{61}$ The recently reported EUVAS IMPROVE trial compared MMF $2 \mathrm{~g} /$ day with AZA $2 \mathrm{mg} / \mathrm{kg}$ /day for the maintenance of remission in vasculitis, after induction with CYP and prednisolone. Perhaps surprisingly, MMF was inferior to AZA in the maintenance of remission in AAV with time to relapse as the primary endpoint. ${ }^{62}$ Therefore, it seems unlikely that MMF will be used as a standard alternative to AZA in maintenance, although it could be used as a second-line agent in relapsing disease or in those intolerant to AZA.

\section{Treatment of relapsing or refractory disease}

Refractory disease is classified as disease that is unresponsive to induction treatment with CYP and steroids or unresponsive to standard maintenance treatment. Whilst true refractory disease is unusual, up to $50 \%$ of patients with AAV will relapse over a five-year period. ${ }^{5}$ Relapse rates are higher in patients with WG and in those with PR3-ANCA. Those who remain ANCA-positive whilst in remission or become ANCA-positive are more likely to relapse. ${ }^{63}$ However, the prognostic significance of a rise in ANCA titer remains unclear. A four-fold rise in ANCA titer has been found to be predictive of relapse but with a variable time interval (mean 5.8 months, range $2-12$ months) and in the same study 6/48 patients experienced relapse whilst ANCA titers were negative or falling. ${ }^{64}$ There have been attempts to treat rising ANCA titers preemptively with increased immunosuppression to avoid relapse. ${ }^{65}$ However, in practice this could lead to overtreatment and thus our approach is to observe frequently in the face of a rising titer and not to cut immunosuppression. Relapse has also been associated with nasal carriage of Staphylococcus aureus in Wegener's granulomatosis and consequently our practice is to maintain most patients with WG on long-term prophylactic cotrimoxazole, ${ }^{30}$ although care needs to be taken with concomitant use of MTX. Most patients under close monitoring who have a minor relapse on baseline immunosuppression can be managed with a temporary increase in oral therapy. Patients with more severe relapse will require addition of one or more agents such as IV glucocorticoids, CYP, infliximab, or RTX to bring relapsing disease under control. Those with multiple relapses may require a change in maintenance regimen.

\section{Leflunomide}

Leflunomide is an oral alternative to AZA or MTX for maintenance in relapsing disease. The mechanism of action of leflunomide is not fully understood but may be related to its ability to inhibit de novo pyrimidine biosynthesis through the inhibition of the enzyme dihydroorotate dehydrogenase. Leflunomide has been shown to be more effective at maintaining remission compared with methotrexate but with an excess of adverse events. ${ }^{66}$ Lower dosing regimens have yet to be evaluated.

\section{Biological therapies TNF blockade}

Infliximab is a chimeric monoclonal antibody which binds soluble and transmembrane forms of TNF- $\alpha$. Blockade of TNF- $\alpha$ with infliximab has been found to be effective for inducing and maintaining remission when used with conventional therapy in an uncontrolled but reasonably large study, and has a steroid-sparing effect, although there is an increased rate of severe infections. ${ }^{67}$ However, a retrospective surveillance study in patients with rheumatoid arthritis treated with TNF inhibitors (predominantly infliximab) also demonstrated an excess risk of active tuberculosis infection. ${ }^{68}$ In contrast with infliximab, the soluble TNFreceptor blocker etanercept was not effective at maintaining remission. Etanercept is a fusion protein consisting of two extracellular p75 TNF- $\alpha$-receptor domains linked to the Fc portion of human IgG1. A randomized controlled trial of etanercept in 180 patients with WG, mainly without severe renal disease, showed no benefit in the induction or maintenance of remission (although prednisolone was withdrawn at six months) and demonstrated a high rate of treatment-associated 
complications and an excess of solid organ tumors. ${ }^{69}$ It is not clear why these two mechanisms of TNF- $\alpha$ blockade gave rise to such different outcomes, and this may relate to their differing biologic effects. The Wegener's Granulomatosis Etanercept Trial also enrolled a significantly greater proportion of relapsing patients into the etanercept arm compared with more treatment-naïve patients in the control arm. Whether this biased the outcomes is unclear.

\section{B-cell depletion}

The success of B-cell depletion with the anti-CD20 chimeric monoclonal antibody RTX in refractory disease ${ }^{70}$ has led to its ongoing evaluation as a remission induction agent. First licensed for B-cell lymphoma, it has been used extensively in hematologic patients and now increasingly in autoimmune disease, including rheumatoid arthritis. RTX is generally well tolerated, but side effects include leucopenia and infection. Rare reports of progressive multifocal leucoencephalopathy in association with RTX and other biologic agents are under evaluation. ${ }^{71}$ The EUVAS RITUXVAS trial compared RTX and two doses of CYP with a standard CYP regimen in 44 patients and found similar remission rates and adverse events, and will be published shortly. ${ }^{72}$ Follow-up remains limited and more prolonged evaluation may be required to evaluate the rates of relapse following B-cell reconstitution. The ongoing RAVE trial compares RTX and steroids with a standard CYP induction regimen in 200 patients, and initial reports suggest equivalent effectiveness at six months. ${ }^{73}$ The RATTRAP trial will compare RTX and infliximab in AAV. Duration of response to RTX can be variable but is frequently prolonged with a median time of $12-16$ months. ${ }^{74}$

\section{Other therapies for refractory disease}

A number of other therapies have been used in small numbers of patients but experience with these is currently limited. 15-Deoxyspergualin is a synthetic version of a protein isolated from Bacillus laterosporus, which binds to chaperone proteins important in the activation of nuclear factor $\kappa \mathrm{B}$ and prevents its activation. It has been trialed in patients with refractory disease and demonstrated an improvement in disease parameters and complete remission in $45 \%$ but led to recurrent leucopenia. ${ }^{75}$ Alemtuzamab is a humanized monoclonal antibody that specifically binds CD52 on the surface of monocytes and lymphocytes. It is used in B-cell lymphoma, allogeneic stem cell transplantation, and renal transplantation. Its use has been reported in a small number of patients with WG with some effect, ${ }^{76}$ but relapse rates and adverse events are common. ${ }^{77}$ Antithymocyte globulin (ATG) is a collection of polyclonal antibodies directed against the surface antigens of activated T-cells and has been used in refractory patients with WG in the EUVAS SOLUTION trial. ${ }^{34}$ T-cell depletion with ATG produced a $75 \%$ remission rate but the development of an antiglobulin response limits repeated therapy. Both ATG and alemtuzumab cause profound immunosuppression and a high rate of severe infections in high-risk subgroups, such as those with renal failure. Of note, both these agents were used in cohorts of patients already exposed to significant immunosuppression, and their role in disease remission in patients naïve to therapy may need to be revisited. IV immunoglobulin has been used to induce remission with significant success ${ }^{78,79}$ either as sole therapy or for its treatment-sparing effect. Although the cost is prohibitive, it may be a useful and safe adjunct in sepsis or pregnancy where standard immunosuppression is contraindicated.

\section{Future prospects in therapy}

The success of RTX has led to the development of further agents for B-cell depletion. A humanized monoclonal antiCD20 antibody, ocrelizumab, has been trialed in a number of autoimmune disorders including rheumatoid arthritis, ${ }^{80}$ and ofatumumab is a fully human anti-CD20 undergoing Phase III trials, which has been used in lymphoproliferative and autoimmune disorders. ${ }^{81}$

Another approach to modulation of B-cells has been proposed following the finding that B-lymphocyte stimulator (BLyS)/B-cell activating factor is a potential mediator in autoimmune disease. ${ }^{82}$ Belimumab, a human anti-BLyS monoclonal antibody, has already shown promise in Phase III trials in SLE. ${ }^{83}$ BLyS is a member of the TNF superfamily of cytokines and is expressed by cells of myeloid origin with a role in B-cell differentiation, proliferation, and immunoglobulin production. Neutrophils are another important source of BLyS. ${ }^{84}$ Serum levels of BLyS have been found to be elevated in $\mathrm{SLE}^{85}$ and AAV. ${ }^{86}$ A proliferation-inducing ligand (APRIL) is another member of the TNF family ${ }^{87}$ and a potent stimulator of B-cell maturation and differentiation. Atacicept is a recombinant fusion protein which blocks both BLyS and APRIL by blocking their receptor TACI (transmembrane activator and calcium modulator and cyclophilin ligand interactor) and has been used in SLE and rheumatoid arthritis. ${ }^{88}$ The role of these B-cell modulating agents in AAV remains to be explored.

A number of other biologic agents which manipulate other aspects of the immune response are either being trialed or are in early use in other diseases. Abatacept, a fusion 
Table 3 Suggested schema for the management of ANCA-associated vasculitis, adapted and updated from Pallan et al ${ }^{98}$

\begin{tabular}{|c|c|c|c|}
\hline Disease severity & EUVAS definition & Induction therapy & Maintenance therapy \\
\hline Localized & $\begin{array}{l}\text { Upper and/or lower respiratory } \\
\text { tract disease without any other } \\
\text { systemic involvement or constitutional } \\
\text { symptoms }\end{array}$ & Methotrexate and steroids & $\begin{array}{l}\text { Low-dose steroids plus azathioprine } \\
\text { or leflunomide or methotrexate } \\
\text { (+ trimethoprim-sulphamethoxazole } \\
\text { also added in WG) }\end{array}$ \\
\hline Early systemic & $\begin{array}{l}\text { Any, without organ-threatening } \\
\text { or life-threatening disease }\end{array}$ & $\begin{array}{l}\text { Methotrexate or cyclophosphamide } \\
\text { and steroids }\end{array}$ & $\begin{array}{l}\text { Low-dose steroids plus azathioprine } \\
\text { or methotrexate }\end{array}$ \\
\hline Generalized & $\begin{array}{l}\text { Renal or other organ threatening } \\
\text { disease, serum creatinine }<500 \mu \mathrm{mol} / \mathrm{L} \\
(5.6 \mathrm{mg} / \mathrm{dL})\end{array}$ & $\begin{array}{l}\text { Cyclophosphamide (or rituximab) } \\
\text { and steroids }\end{array}$ & $\begin{array}{l}\text { Low-dose steroids plus azathioprine } \\
\text { Mycophenolate mofetil as second-line } \\
\text { agent }\end{array}$ \\
\hline Severe & $\begin{array}{l}\text { Renal or other vital organ failure, serum } \\
\text { creatinine }>500 \mu \mathrm{mol} / \mathrm{L}(5.6 \mathrm{mg} / \mathrm{dL})\end{array}$ & $\begin{array}{l}\text { Cyclophosphamide and steroids plus } \\
\text { plasma exchange (rituximab instead } \\
\text { of CYC) }\end{array}$ & $\begin{array}{l}\text { Low-dose steroids plus azathioprine } \\
\text { Mycophenolate mofetil as second-line } \\
\text { agent }\end{array}$ \\
\hline Refractory & $\begin{array}{l}\text { Progressive disease unresponsive to } \\
\text { glucocorticoids and cyclophosphamide }\end{array}$ & $\begin{array}{l}\text { Deoxyspergualin, antithymocyte } \\
\text { globulin, or rituximab }\end{array}$ & No consensus \\
\hline
\end{tabular}

protein of CTLA4-Ig which selectively modulates T-cell co-stimulation by blocking the engagement of CD28, would theoretically be of benefit in AAV, although the EUVAS ABAVAS trial was terminated early due to slow recruitment. The alternative pathway of complement has been shown to have a role in a murine model of MPO-ANCA vasculitis. ${ }^{22}$ Addition of a C5-inhibiting monoclonal antibody in this model markedly protected against glomerulonephritis. ${ }^{89}$ Eculizumab is a monoclonal antibody to C5a used in the treatment of paroxysmal nocturnal hemoglobinuria. If a role for complement can also be demonstrated in the pathology of human AAV then modulation of this pathway may be a therapeutic prospect. An anti-IL-5 monoclonal antibody, mepolizumab, has been effective in hypereosinophilic syndromes ${ }^{90}$ and may be of use in CSS which is associated with elevated IL-5 and eosinophilia. Tocilizumab, an antiIL-6 monoclonal, has been used in refractory rheumatoid arthritis $^{91}$ and may be more widely applicable in autoimmune diseases.

The Th17 subset of T-helper cells which produce IL-17 has been implicated in the pathogenesis of a number of experimental and human autoimmune conditions. This is particularly of relevance to AAV because IL-17 deficient mice are protected from nephrotoxic nephritis ${ }^{92}$ and from MPO-ANCA vasculitis, ${ }^{93}$ and Th17 cells have recently been shown to induce proliferative glomerulonephritis in mice. ${ }^{94}$ Clinical trials of IL-17 blockade are already underway in autoimmune uveitis, psoriatic arthritis, ankylosing spondylitis, and Crohn's disease (www.clinicaltrials.gov) and may have potential for use in AAV. Inhibition of spleen tyrosine kinase (Syk) has been trialed in rheumatoid arthritis ${ }^{95}$ and has been shown in our laboratory to prevent and treat nephrotoxic nephritis in rats. ${ }^{96}$ Syk inhibition might be an important therapeutic target in AAV. Lastly, stem cell transplantation aims to restore immunologic tolerance by eliminating autoreactive clones followed by T-cell reconstitution. There have been some cases of hematopoietic stem cell transplantation in patients with unresponsive ANCA-positive vasculitis but ANCA-associated disease relapse is not completely prevented, and therefore its value has yet to be confirmed prospectively. ${ }^{97}$

\section{Conclusion}

Current approaches to treatment in induction and maintenance of AAV are well established (Table 3).$^{98}$ The European League against Rheumatism (EULAR) guidelines for the management of small and medium vessel vasculitis have recently been published ${ }^{99}$ and the role of newer agents such as MMF is being defined by clinical trials. The success and safety profile of rituximab in refractory disease has led to trials in maintenance and induction therapy which may see it recommended as standard practice, although high cost may limit its use. The wide range of newer biologic agents now available brings huge possibilities for immunotherapy in relapsing or refractory disease. However, the rarity of AAV is a hindrance to developing an evidence base for practice. Therefore, international cooperation and collaborative trials remain essential if patients are to receive appropriate, effective therapy.

\section{Disclosures}

The authors report no conflict of interest in this research. 


\section{References}

1. Booth AD, Almond MK, Burns A, et al. Outcome of ANCA-associated renal vasculitis: A 5-year retrospective study. Am J Kidney Dis. 2003;41(4):776-784.

2. Walton EW. Giant-cell granuloma of the respiratory tract (Wegener's granulomatosis). BMJ. 1958;2(5091):265-270.

3. Jayne D, Rasmussen N, Andrassy K, et al. A randomized trial of maintenance therapy for vasculitis associated with antineutrophil cytoplasmic autoantibodies. $N$ Engl J Med. 2003;349(1):36-40.

4. Matteson EL, Gold KN, Bloch DA, Hunder GG. Long-term survival of patients with Wegener's granulomatosis from the American College of Rheumatology Wegener's Granulomatosis Classification Criteria Cohort. Am J Med. 1996;101(2):129-134.

5. Westman KW, Bygren PG, Olsson H, Ranstam J, Wieslander J. Relapse rate, renal survival, and cancer morbidity in patients with Wegener's granulomatosis or microscopic polyangiitis with renal involvement. J Am Soc Nephrol. 1998;9(5):842-852.

6. Hoffman GS, Kerr GS, Leavitt RY, et al. Wegener granulomatosis: An analysis of 158 patients. Ann Intern Med. 1992;116(6):488-498.

7. Jennette JC, Falk RJ, Andrassy K, et al. Nomenclature of systemic vasculitides. Proposal of an international consensus conference. Arthritis Rheum. 1994;37(2):187-192.

8. Watts RA, Lane SE, Bentham G, Scott DG. Epidemiology of systemic vasculitis: A ten-year study in the United Kingdom. Arthritis Rheum. 2000;43(2):414-419.

9. European therapeutic trials in ANCA-associated systemic vasculitis: Disease scoring, consensus regimens and proposed clinical trials. European Community Study Group on Clinical Trials in Systemic Vasculitis ECSYSVASTRIAL. Clin Exp Immunol. 1995;101 Suppl 1:29.

10. Hagen EC, Daha MR, Hermans J, et al. Diagnostic value of standardized assays for anti-neutrophil cytoplasmic antibodies in idiopathic systemic vasculitis. EC/BCR Project for ANCA Assay Standardization. Kidney Int. 1998;53(3):743-753.

11. Mukhtyar C, Lee R, Brown D, et al. Modification and validation of the Birmingham Vasculitis Activity Score (version 3). Ann Rheum Dis. 2009;68(12):1827-1832.

12. Exley AR, Bacon PA, Luqmani RA, et al. Development and initial validation of the Vasculitis Damage Index for the standardized clinical assessment of damage in the systemic vasculitides. Arthritis Rheum. 1997;40(2):371-380.

13. Mulder AH, Heeringa P, Brouwer E, Limburg PC, Kallenberg CG. Activation of granulocytes by anti-neutrophil cytoplasmic antibodies (ANCA): A Fc gamma RII-dependent process. Clin Exp Immunol. 1994;98(2):270-278.

14. Williams JM, Ben-Smith A, Hewins P, et al. Activation of the G(i) heterotrimeric $\mathrm{G}$ protein by ANCA IgG F(ab')2 fragments is necessary but not sufficient to stimulate the recruitment of those downstream mediators used by intact ANCA IgG. J Am Soc Nephrol. 2003;14(3):661-669.

15. Harper L, Cockwell P, Adu D, Savage CO. Neutrophil priming and apoptosis in anti-neutrophil cytoplasmic autoantibody-associated vasculitis. Kidney Int. 2001;59(5):1729-1738.

16. Hattar K, Bickenbach A, Csernok E, et al. Wegener's granulomatosis: Antiproteinase 3 antibodies induce monocyte cytokine and prostanoid release-role of autocrine cell activation. J Leukoc Biol. 2002;71(6): 996-1004

17. Radford DJ, Savage CO, Nash GB. Treatment of rolling neutrophils with antineutrophil cytoplasmic antibodies causes conversion to firm integrin-mediated adhesion. Arthritis Rheum. 2000;43(6):1337-1345.

18. Cockwell P, Brooks CJ, Adu D, Savage CO. Interleukin-8: A pathogenetic role in antineutrophil cytoplasmic autoantibody-associated glomerulonephritis. Kidney Int. 1999;55(3):852-863.

19. Harper L, Ren Y, Savill J, Adu D, Savage CO. Antineutrophil cytoplasmic antibodies induce reactive oxygen-dependent dysregulation of primed neutrophil apoptosis and clearance by macrophages. Am J Pathol. 2000;157(1):211-220.
20. Bansal PJ, Tobin MC. Neonatal microscopic polyangiitis secondary to transfer of maternal myeloperoxidase-antineutrophil cytoplasmic antibody resulting in neonatal pulmonary hemorrhage and renal involvement. Ann Allergy Asthma Immunol. 2004;93(4):398-401.

21. Xiao H, Heeringa $\mathrm{P}, \mathrm{Hu} \mathrm{P}$, et al. Antineutrophil cytoplasmic autoantibodies specific for myeloperoxidase cause glomerulonephritis and vasculitis in mice. J Clin Invest. 2002;110(7):955-963.

22. Xiao H, Schreiber A, Heeringa P, Falk RJ, Jennette JC. Alternative complement pathway in the pathogenesis of disease mediated by antineutrophil cytoplasmic autoantibodies. Am J Pathol. 2007;170(1): 52-64.

23. Xiao H, Heeringa $\mathrm{P}$, Liu Z, et al. The role of neutrophils in the induction of glomerulonephritis by anti-myeloperoxidase antibodies. Am J Pathol. 2005;167(1):39-45.

24. Little MA, Smyth CL, Yadav R, et al. Antineutrophil cytoplasm antibodies directed against myeloperoxidase augment leukocytemicrovascular interactions in vivo. Blood. 2005;106(6):2050-2058.

25. Pfister H, Ollert M, Frohlich LF, et al. Antineutrophil cytoplasmic autoantibodies against the murine homolog of proteinase 3 (Wegener autoantigen) are pathogenic in vivo. Blood. 2004;104(5):1411-1418.

26. Pinching AJ, Rees AJ, Pussell BA, Lockwood CM, Mitchison RS, Peters DK. Relapses in Wegener's granulomatosis: The role of infection. BMJ. 1980;281(6244):836-838.

27. Kain R, Exner M, Brandes R, et al. Molecular mimicry in pauciimmune focal necrotizing glomerulonephritis. Nat Med. 2008;14(10): 1088-1096.

28. Pendergraft WF 3rd, Preston GA, Shah RR, et al. Autoimmunity is triggered by cPR-3(105-201), a protein complementary to human autoantigen proteinase-3. Nat Med. 2004;10(1):72-79.

29. Stegeman CA, Tervaert JW, Sluiter WJ, Manson WL, de Jong PE, Kallenberg CG. Association of chronic nasal carriage of Staphylococcus aureus and higher relapse rates in Wegener granulomatosis. Ann Intern Med. 1994;120(1):12-17.

30. Stegeman CA, Tervaert JW, de Jong PE, Kallenberg CG. Trimethoprimsulfamethoxazole (co-trimoxazole) for the prevention of relapses of Wegener's granulomatosis. Dutch Co-Trimoxazole Wegener Study Group. N Engl J Med. 1996;335(1):16-20.

31. Cunningham MA, Huang XR, Dowling JP, Tipping PG, Holdsworth SR. Prominence of cell-mediated immunity effectors in "pauci-immune" glomerulonephritis. J Am Soc Nephrol. 1999;10(3):499-506.

32. Lamprecht P, Gross WL. Current knowledge on cellular interactions in the WG-granuloma. Clin Exp Rheumatol. 2007;25(1 Suppl 44): S49-S51.

33. Griffith ME, Coulthart A, Pusey CD. T cell responses to myeloperoxidase (MPO) and proteinase 3 (PR3) in patients with systemic vasculitis. Clin Exp Immunol. 1996;103(2):253-258.

34. Schmitt WH, Hagen EC, Neumann I, et al. Treatment of refractory Wegener's granulomatosis with antithymocyte globulin (ATG): An open study in 15 patients. Kidney Int. 2004;65(4):1440-1448.

35. Nogueira E, Hamour S, Sawant D, et al. Serum IL-17 and IL-23 levels and autoantigen-specific Th17 cells are elevated in patients with ANCA-associated vasculitis. Nephrol Dial Transplant. Jan 25, 2010. [Epub ahead of print].

36. Muller Kobold AC, Kallenberg CG, Tervaert JW. Monocyte activation in patients with Wegener's granulomatosis. Ann Rheum Dis. 1999;58(4):237-245.

37. Mahr AD, Neogi T, Merkel PA. Epidemiology of Wegener's granulomatosis: Lessons from descriptive studies and analyses of genetic and environmental risk determinants. Clin Exp Rheumatol. 2006; 24(2 Suppl 41):S82-S91.

38. Carr EJ, Clatworthy MR, Lowe CE, et al. Contrasting genetic association of IL2RA with SLE and ANCA-associated vasculitis. BMC Med Genet. 2009;10:22.

39. Carr EJ, Niederer HA, Williams J, et al. Confirmation of the genetic association of CTLA4 and PTPN22 with ANCA-associated vasculitis. BMC Med Genet. 2009;10:121. 
40. Rarok AA, Stegeman CA, Limburg PC, Kallenberg CG. Neutrophil membrane expression of proteinase 3 (PR3) is related to relapse in PR3-ANCA-associated vasculitis. J Am Soc Nephrol. 2002;13(9): 2232-2238.

41. Alcorta DA, Barnes DA, Dooley MA, et al. Leukocyte gene expression signatures in antineutrophil cytoplasmic autoantibody and lupus glomerulonephritis. Kidney Int. 2007;72(7):853-864.

42. Jayne D. Update on the European Vasculitis Study Group trials. Curr Opin Rheumatol. 2001;13(1):48-55.

43. Fauci AS, Haynes BF, Katz P, Wolff SM. Wegener's granulomatosis: Prospective clinical and therapeutic experience with 85 patients for 21 years. Ann Intern Med. 1983;98(1):76-85.

44. de Groot K, Harper L, Jayne DR, et al. Pulse versus daily oral cyclophosphamide for induction of remission in antineutrophil cytoplasmic antibody-associated vasculitis: A randomized trial. Ann Intern Med. 2009;150(10):670-680.

45. Jayne DR, Gaskin G, Rasmussen N, et al. Randomized trial of plasma exchange or high-dosage methylprednisolone as adjunctive therapy for severe renal vasculitis. J Am Soc Nephrol. 2007;18(7):2180-2188.

46. de Groot K, Rasmussen N, Bacon PA, et al. Randomized trial of cyclophosphamide versus methotrexate for induction of remission in early systemic antineutrophil cytoplasmic antibody-associated vasculitis. Arthritis Rheum. 2005;52(8):2461-2469.

47. Hu W, Liu C, Xie H, Chen H, Liu Z, Li L. Mycophenolate mofetil versus cyclophosphamide for inducing remission of ANCA vasculitis with moderate renal involvement. Nephrol Dial Transplant. 2008;23(4):1307-1312.

48. Hogan SL, Falk RJ, Chin H, et al. Predictors of relapse and treatment resistance in antineutrophil cytoplasmic antibody-associated smallvessel vasculitis. Ann Intern Med. 2005;143(9):621-631.

49. Talar-Williams C, Hijazi YM, Walther MM, et al. Cyclophosphamideinduced cystitis and bladder cancer in patients with Wegener granulomatosis. Ann Intern Med. 1996;124(5):477-484

50. Reinhold-Keller E, Fink CO, Herlyn K, Gross WL, de Groot K. High rate of renal relapse in 71 patients with Wegener's granulomatosis under maintenance of remission with low-dose methotrexate. Arthritis Rheum. 2002;47(3):326-332.

51. Langford CA, Talar-Williams C, Barron KS, Sneller MC. Use of a cyclophosphamide-induction methotrexate-maintenance regimen for the treatment of Wegener's granulomatosis: Extended follow-up and rate of relapse. Am J Med. 2003;114(6):463-469.

52. Pagnoux C, Mahr A, Hamidou MA, et al. Azathioprine or methotrexate maintenance for ANCA-associated vasculitis. $N$ Engl J Med 2008;359(26):2790-2803.

53. Mayer AD, Dmitrewski J, Squifflet JP, et al. Multicenter randomized trial comparing tacrolimus (FK506) and cyclosporine in the prevention of renal allograft rejection: A report of the European Tacrolimus Multicenter Renal Study Group. Transplantation. 1997;64(3):436-443.

54. Haubitz M, Koch KM, Brunkhorst R. Cyclosporin for the prevention of disease reactivation in relapsing ANCA-associated vasculitis. Nephrol Dial Transplant. 1998;13(8):2074-2076.

55. Kawasaki S, Nakamura H, Honda E, et al. Tacrolimus as a reinforcement therapy for a patient with MPO-ANCA-associated diffuse alveolar hemorrhage. Clin Rheumatol. 2007;26(7):1211-1214.

56. Tokuda M, Kurata N, Mizoguchi A, et al. Effect of low-dose cyclosporin A on systemic lupus erythematosus disease activity. Arthritis Rheum. 1994;37(4):551-558.

57. Manger K, Kalden JR, Manger B. Cyclosporin A in the treatment of systemic lupus erythematosus: Results of an open clinical study. $\mathrm{Br} J$ Rheumatol. 1996;35(7):669-675.

58. Caccavo D, Lagana B, Mitterhofer AP, et al. Long-term treatment of systemic lupus erythematosus with cyclosporin A. Arthritis Rheum. 1997;40(1):27-35

59. Mok CC, Tong KH, To CH, Siu YP, Au TC. Tacrolimus for induction therapy of diffuse proliferative lupus nephritis: An open-labeled pilot study. Kidney Int. 2005;68(2):813-817.
60. A blinded, randomized clinical trial of mycophenolate mofetil for the prevention of acute rejection in cadaveric renal transplantation. The Tricontinental Mycophenolate Mofetil Renal Transplantation Study Group. Transplantation. 1996;61(7):1029-1037.

61. Langford CA, Talar-Williams C, Sneller MC. Mycophenolate mofetil for remission maintenance in the treatment of Wegener's granulomatosis. Arthritis Rheum. 2004;51(2):278-283.

62. Hiemstra TH, Walsh MW, Schmitt WH, Jayne D. Randomised controlled trial of mycophenolate mofetil versus azathioprine for maintenance therapy in ANCA-Associated vasculitis (IMPROVE). 1-4th Nov American Society of Nephrology 2009: SA-FC331A.

63. Girard T, Mahr A, Noel LH, et al. Are antineutrophil cytoplasmic antibodies a marker predictive of relapse in Wegener's granulomatosis? A prospective study. Rheumatology (Oxford). 2001;40(2):147-151.

64. Han WK, Choi HK, Roth RM, McCluskey RT, Niles JL. Serial ANCA titers: Useful tool for prevention of relapses in ANCA-associated vasculitis. Kidney Int. 2003;63(3):1079-1085.

65. Tervaert JW, Huitema MG, Hene RJ, et al. Prevention of relapses in Wegener's granulomatosis by treatment based on antineutrophil cytoplasmic antibody titre. Lancet. 1990;336(8717):709-711.

66. Metzler C, Miehle N, Manger K, et al. Elevated relapse rate under oral methotrexate versus leflunomide for maintenance of remission in Wegener's granulomatosis. Rheumatology (Oxford). 2007;46(7):1087-1091.

67. Booth A, Harper L, Hammad T, et al. Prospective study of TNF alpha blockade with infliximab in anti-neutrophil cytoplasmic antibodyassociated systemic vasculitis. J Am Soc Nephrol. 2004;15(3):717-721.

68. Gomez-Reino JJ, Carmona L, Valverde VR, et al. Treatment of rheumatoid arthritis with tumor necrosis factor inhibitors may predispose to significant increase in tuberculosis risk: A multicenter activesurveillance report. Arthritis Rheum. 2003;48(8):2122-2127.

69. Wegener's Granulomatosis Etanercept Trial Research Group. Etanercept plus standard therapy for Wegener's granulomatosis. $N$ Engl J Med. 2005;352(4):351-361.

70. Jones RB, Ferraro AJ, Chaudhry AN, et al. A multicenter survey of rituximab therapy for refractory antineutrophil cytoplasmic antibodyassociated vasculitis. Arthritis Rheum. 2009;60(7):2156-2168.

71. Carson KR, Evens AM, Richey EA, et al. Progressive multifocal leukoencephalopathy after rituximab therapy in HIV-negative patients: A report of 57 cases from the Research on Adverse Drug Events and Reports project. Blood. 2009;113(20):4834-4840.

72. Jones R, Tervaert JW, Hauser T, et al. Randomized trial of rituximab vs cyclophosphamide for ANCA-associated renal vasculitis: RITUXVAS Proceedings of the 14th International Vasculitis and ANCA workshop. 6-9 Jun, 2009. Lund Sweden. APMIS. 2009;117(S127):A22.

73. Specks U. Rituximab for ANCA-associated vasculitis (the RAVEtrial). Presented at: 14th International Vasculitis and ANCA workshop. 6-9 Jun 2009. Lund, Sweden.

74. Smith KG, Jones RB, Burns SM, Jayne DR. Long-term comparison of rituximab treatment for refractory systemic lupus erythematosus and vasculitis: Remission, relapse, and re-treatment. Arthritis Rheum. 2006;54(9):2970-2982.

75. Birck R, Warnatz K, Lorenz HM, et al. 15-Deoxyspergualin in patients with refractory ANCA-associated systemic vasculitis: A six-month open-label trial to evaluate safety and efficacy. J Am Soc Nephrol. 2003;14(2):440-447.

76. Lockwood CM, Thiru S, Stewart S, et al. Treatment of refractory Wegener's granulomatosis with humanized monoclonal antibodies. QJM. 1996;89(12):903-912.

77. Walsh M, Chaudhry A, Jayne D. Long-term follow-up of relapsing/ refractory anti-neutrophil cytoplasm antibody associated vasculitis treated with the lymphocyte depleting antibody alemtuzumab (CAMPATH-1H). Ann Rheum Dis. 2008;67(9):1322-1327.

78. Martinez V, Cohen P, Pagnoux C, et al. Intravenous immunoglobulins for relapses of systemic vasculitides associated with antineutrophil cytoplasmic autoantibodies: Results of a multicenter, prospective, open-label study of twenty-two patients. Arthritis Rheum. 2008;58(1):308-317. 
79. Jayne DR, Lockwood CM. Intravenous immunoglobulin as sole therapy for systemic vasculitis. Br J Rheumatol. 1996;35(11):1150-1153.

80. Genovese MC, Kaine JL, Lowenstein MB, et al. Ocrelizumab, a humanized anti-CD20 monoclonal antibody, in the treatment of patients with rheumatoid arthritis: A phase I/II randomized, blinded, placebo-controlled, dose-ranging study. Arthritis Rheum. 2008;58(9):2652-2661.

81. Castillo J, Milani C, Mendez-Allwood D. Ofatumumab, a secondgeneration anti-CD20 monoclonal antibody, for the treatment of lymphoproliferative and autoimmune disorders. Expert Opin Investig Drugs. 2009;18(4):491-500.

82. Gross JA, Johnston J, Mudri S, et al. TACI and BCMA are receptors for a TNF homologue implicated in B-cell autoimmune disease. Nature. 2000;404(6781):995-999.

83. Trial watch: BLYS-targeted antibody shows promise in Phase III SLE trial. Nat Rev Drug Discov. 2009;8(9):688.

84. Scapini P, Nardelli B, Nadali G, et al. G-CSF-stimulated neutrophils are a prominent source of functional BLyS. J Exp Med. 2003;197(3): 297-302.

85. Petri M, Stohl W, Chatham W, et al. Association of plasma B lymphocyte stimulator levels and disease activity in systemic lupus erythematosus. Arthritis Rheum. 2008;58(8):2453-2459.

86. Krumbholz M, Specks U, Wick M, Kalled SL, Jenne D, Meinl E. BAFF is elevated in serum of patients with Wegener's granulomatosis. J Autoimmun. 2005;25(4):298-302.

87. Hahne M, Kataoka T, Schroter M, et al. APRIL, a new ligand of the tumor necrosis factor family, stimulates tumor cell growth. J Exp Med. 1998;188(6):1185-1190.

88. Nestorov I, Munafo A, Papasouliotis O, Visich J. Pharmacokinetics and biological activity of atacicept in patients with rheumatoid arthritis. J Clin Pharmacol. 2008;48(4):406-417.

89. Huugen D, van Esch A, Xiao H, et al. Inhibition of complement factor C5 protects against anti-myeloperoxidase antibody-mediated glomerulonephritis in mice. Kidney Int. 2007;71(7):646-654.

90. Rothenberg ME, Klion AD, Roufosse FE, et al. Treatment of patients with the hypereosinophilic syndrome with mepolizumab. N Engl J Med. 2008;358(12):1215-1228.
91. Kawashiri SY, Kawakami A, Iwamoto N, et al. Switching to the antiinterleukin-6 receptor antibody tocilizumab in rheumatoid arthritis patients refractory to antitumor necrosis factor biologics. Mod Rheumatol. 2010;20(1):40-45.

92. Paust HJ, Turner JE, Steinmetz OM, et al. The IL-23/Th17 axis contributes to renal injury in experimental glomerulonephritis. $J \mathrm{Am}$ Soc Nephrol. 2009;20(5):969-979.

93. Gan PY, Steinmetz OM, Tan DS, et al. Th17 cells promote autoimmune anti-myeloperoxidase glomerulonephritis. J Am Soc Nephrol. 2010; Mar 18 [Epub ahead of print].

94. Summers SA, Steinmetz OM, Li M, et al. Th1 and Th17 cells induce proliferative glomerulonephritis. J Am Soc Nephrol. 2009;20(12): 2518-2524.

95. Weinblatt ME, Kavanaugh A, Burgos-Vargas R, et al. Treatment of rheumatoid arthritis with a Syk kinase inhibitor: A twelve-week, randomized, placebo-controlled trial. Arthritis Rheum. 2008;58(11): 3309-3318.

96. Smith J, McDaid J, Bhangal G, et al. Treatment with a spleen tyrosine kinase inhibitor reduces the severity of established antibody-mediated glomerulonephritis. J Am Soc Nephrol. 2010;21(2):231-236.

97. Daikeler T, Kotter I, Bocelli Tyndall C, et al. Haematopoietic stem cell transplantation for vasculitis including Behcet's disease and polychondritis: A retrospective analysis of patients recorded in the European Bone Marrow Transplantation and European League Against Rheumatism databases and a review of the literature. Ann Rheum Dis. 2007;66(2):202-207.

98. Pallan L, Savage CO, Harper L. ANCA-associated vasculitis: From bench research to novel treatments. Nat Rev Nephrol. 2009;5(5): 278-286.

99. Mukhtyar C, Guillevin L, Cid MC, et al. EULAR recommendations for the management of primary small and medium vessel vasculitis. Ann Rheum Dis. 2009;68(3):310-317.
Therapeutics and Clinical Risk Management

\section{Publish your work in this journal}

Therapeutics and Clinical Risk Management is an international, peerreviewed journal of clinical therapeutics and risk management, focusing on concise rapid reporting of clinical studies in all therapeutic areas, outcomes, safety, and programs for the effective, safe, and sustained use of medicines. This journal is indexed on PubMed Central, CAS,

\section{Dovepress}

EMBase, Scopus and the Elsevier Bibliographic databases. The manuscript management system is completely online and includes a very quick and fair peer-review system, which is all easy to use. Visit http://www.dovepress.com/testimonials.php to read real quotes from published authors. 